\title{
Ein Nachtrag.
}

Die in dem kleinen Aufsatz FUF XXIV, 288-91 behandelte Erscheinung, dass ein Verbum, das $n$ e h m e n bedeutet, einem anderen Verbum gleichgeordnet, diesem die Bedentung des schnellen Vollzuges zufügt, ist weiter verbreitet, als ich damals wusste. In dem "Bau der europäischen Sprachen" (1942) schrieb ich, dass sie schwed., dän., finn., lapp., mordw., tscherem., russ., ist, S. 73 a.1. Dafür möchte ich, über das FUF XXIV bemerkte hinaus, den Beweis - und dann noch eine nicht unwichtige Ergänzung - geben.

Zunächst also das Lappische. Trotz meiner sehr geringen Belesenheit hier kann ich sichere Beispiele bieten. Gexetz, Wörterbuch der Kola-lappischen Dialekte, 1891, hat unter nr. 1900 (VALTA-) . . .: wird auch vor anderen Zeitwörtern als Verstärkung od. zur Veranschaulichung der Handlung gebraucht: konagas $v \bar{a}_{i} l t i$, ${ }_{i}$ jive $\bar{c}_{i}$ ij kuningas otti ja hakkasi pään poikki / der König (nahm und) enthauptete ihn" - wo die in der deutschen Übersetzung beigefügte Einklammerung ron "nahm und" wohl andeutet, dass die Fügung nicht deutsch, wohl aber auch finnisch ist. In den Texten ist $\mathrm{S}$. $276 K \bar{a}_{i} l e s$ $v \vec{a}_{i} l t i$ rieka $a_{i} d i j(239,13)$ - richtig - nur mit "Der Alte wacht auf» übersetzt. Qvigstad, der unermüdliche, gewährt mir in seinen "Lappischen Texten aus Kalfjord und Helgöy", 1925, S. 26, 27: $D e$ valdi A čhenne, lai' $k i$ gor'nedunno 'da leerte sie (Ačhenne) eine Tonne Korn aus', und ebenda: $D e$ valdi ja čuörvoi cicačaid alcis vak' 'ken 'da rief sie die Vögelchen zu Hilfe'. In den "Lappischen Erzählungen aus Hatfjelldalen", 1924, lesen wir, S. 260: Dihte samie väldi jeh nuoleti stalu garvu jeh ječsesse gorvuti; stalub jes väldi jeh smäiri $d_{E}$ nnie stuore drukien sisnio 'der Lappe zog die Kleider des Stallo ab und zog sie selbst an; den Stallo zerstückelte er 
in dem grossen Troge'. Diese Beispiele möchte ich besonders herrorheben, weil, wer die Sprache nicht "kann" oder nicht kennt, gewiss übersetzt hätte: "der Lappe nahm (den Stallo) und zog ihm die Kleider ab» —, was ja zweifellos auch einen ähnlichen Sinn ergäbe, aber eben "falsch» wäre. So finden wir denn auch im dritten Bande des grossartigen lappischen Wörterbuches von Nielsen, 1938, S. 730 unter val'det 4. "with inf.: begin to (of an uncompleted action); connected with another rerb by $j \hat{a}$ 'and': go and ... (of a completed action)". Cnd so hat diese Fügung auch Kxut BERGsLaxd in seiner komplizierten und äüsserst anregenden Roros-Lappisk Grammatikk, 1946, an der richtigen Stelle unter "Verbale jukstaposisjonsgrupper», $\S 284.2$ verzeichnet.

Wir können uns jetzt mit grösserer Sicherheit den mordwinischen Beispielen nähern. Schachmatov übersetzt den Satz: Synst ke•řest saśt', sa·jiż i poverź po·ṕónt' mit on разсердпгись Іг повђсппи попа, Sbornik, 1910, S. 9, d.h. einfach durch die perfe $\mathrm{k} t$ i ve Form des Verbums. S. 20 aller-

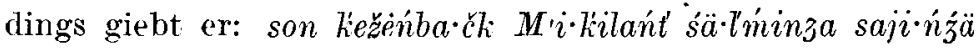
dy ta·rginźä mit онъ въ сердцахъ взя.тъ пі вырвалт у Николы глаза. Взялъ ist vielleicht hier so zu verstehen wie FLF XXIV 290. Für das Mokšanische hat Ravila uns durch die sehr rerdienstliche Herausgabe von Paasonens Material mit reichlichem Stoffe versorgt, 1947. Hier finden wir nun Beispiele, wo es uns schwer wird an eine nur effektivierende Bedeutung von śärams 'nehmen' zu glauben: son säźzżä liaronnts otśazârś putâżä saldatt' pras $(835,1)$ 'der Kaiser nahm seine Krone, setzte sie dem Soldaten auf den Kopf; särśs kieŕan pa·rgañä $i$ puć ezânzâ raj-ṕenš dâ med'-ṕenš $(839,4)$ er nahm einen Korb aus Rinde und legte einen Butterlöffel und einen Honiglöffel hinein'; $i$ sạvanżä varćiś ńän mar'tânza $i$ kứs tumât'pra's $(842,9)$ ' und die Krähe nahm sie mit sich und stieg auf den Gipfel der Eiche' (ähnlich 839, 7); sävezä sońgä $i$ kunda.śt' pratks $(851,8)$ 'er nahm auch ihn mit und sie gesellten sich zu einander wie Brüder'; sävezä alašants, vätsị käd-pesânza $(843,6)$ 'er nahm sein Pferd und führte es an der Hand'. Hier folgt aber auch auf das Verb säuvams stets ein Nomen (Objekt oder/und Subjekt), nie das andere Verb 
unmittelbar, wie in den folgenden Beispielen: son säávaźi $i$ muśkizźn $(808,2)$ 'sie nahm sie und wusch sie; sojú śäveźä śimd’aźä andôzäa $(818,8)$ 'sie nahm ihn, gab ihm Trinken und Essen'; sävezä $i$ jordazä šudi vets $(859,4)$ 'sie nahm es, warf es in ein fliessendes Wasser'; son avaś śä́śs, kšt'ritś aškaraf śứä $(826,3)$ 'die Frau nahm, spann einen Knäüel Garn'. Diese Fälle entsprechen durchaus den angeführten lappischen, und so würde ich auch in der Übersetzung ron son säúśs salda.tś, sormatś sormañä $(830,3)$ 'der Soldat nahm, schrieb einen Brief': "nahm", weglassen. Ebenso heisst: aläs sävez ä $i$ lokšasa piksazä $(848,3)$ kaum 'der Mann packte ihn und prügelte ihn mit seiner Peitsche', sondern 'der Mann prügelte ihn mit der Peitsche $\mathrm{d} \mathrm{u} \mathrm{r} \mathrm{ch}$ '. Entsprechend möchte ich: son salazä, sävezä kandâzä pajart' kudânts vakss $(890,9)$ 'Er stahl ihn und nahm ihn mit.Er trug ihn nach dem Hause des Bojaren' auffassen und würde $(875,12)$ sävezä, menelti kutśftezä i nterpungieren und 'er brachte ihn zum Himmel hinauf' übersetzen.

Dass die Fügung im Tscheremissischen gewöhnlich ist, hat in seiner Besprechung der grossen Beke'schen Textsammlung Räsänen, Magyar Nyelvőr 67, 1938, S. 123 bemerkt und ich in der Besprechung desselben Werkes im JRAS. Räsänen vergleicht richtig das finnische otti $j$ a meni, das er ung. mit: fogta magát és elment wiedergiebt. Beke war die Struktur, wie seine merkwürdige Übersetzung wer stellt sich dazu», die später durch die bessere ser macht sich daran" ersetzt ist, nicht klar; maine Bemerkungen FUF XXIV hätten vielleicht auf das richtige führen können.

Dass diese Struktur in einem geographisch zusammenhängenden, nordeuropäischen Gebiete zu finden its, dürfte nun klar sein. Ob es aber eine Methode giebt, die uns ermöglichen könnte, den Ausgangspunkt zu bestimmen, weiss ich nicht. Dazu hilft auch nicht die Tatsache, die mir erst jezt bekannt geworden ist, dass diese Struktur auch altnordisch ist. In dem Glossar zu Wimmer's Oldnordisk Læsebog ${ }^{9}$ (1929) finden wir S. 292 b: tóku peir ok gerðu sér net, (som på dansk) 'de tog og gjorde sig et næt' o: gav sig til at lave et næt (aus der Snorra Edda), taka peir nu siðan og drekka erfit (aus der 
Jómsríkínga Saga). Zwar sind diese Beispiele älter als die oben beigebrachten. Aber sie beweisen natürlich nicht, dass diese Fügung aus dem Nitnordischen stammt. Ich glaube, sie wird sich noch in manchen Sprachen dieses Gebietes finden, rielleicht auch in anderen, diese Fügung, die so deutlich einer beschränkten Logik kein Genüge tut. So selbstverständlich es für uns ist, dass Worte mit der Bedeutung 'nehmen' vor einem Verb in einer Nominalform (Infinitiv) 'anfangen' bedeuten, so überraschend ist es für uns, dass ein Verb derselben Bedeutung 'nehmen' perfektivierend wirkt. Vielleicht könnte man aber in der Geschichte der indogermanischen -sk-Bildungen ähnliches finden. Jedenfalls aber ist die logische Fremdheit der Grund, dass diese Fügung so oft - zunächst ja auch von mir - missverstanden worden ist.

ERNST LEWY.

Rathfarnham, Co. Dublin, den 5. Jannar 1948. 